\title{
Probable Optimization of Reactive Power in distribution systems, in presence of distributed generation sources conjugated to network and islanding
}

\author{
QolamrezaNematollahi, EsmailKhalilzadeh, MohammadrezaAghaei, \\ MojtabaBorhani \\ 12Azad University Branch of Marvdasht \\ 34 AzerbaijanPower Consulting Engineering Company
}

\begin{abstract}
In this article Probable Optimization of Reactive Power in distribution systems, in presence of distributed generation sources conjugated to network and islanding has been presented.For probable assessment of success operation of micro grids based on active and reactive power quality and consideration of voltage limitation, a systematic and optimized strategy for optimum placement of generation resources has been presented. The problem has been solved by the taboo search optimization algorithm and consideration of two objective function. First objective function is the annual energy loss and second one is a novel index in micro grid succession assessment based on active and reactive power quality and voltage limitations. Then the reactive optimum power is designed for reduction of annual energy loss of systems conjugated to network.

By a case study in this article it will be shown that placement location and the amount of distributed generation resources have the considerable effect on micro grids operations.
\end{abstract}

Keywords: Energy loss, micro grid operation, optimum placement, reactive power designing, taboo search.

\section{Introduction}

Distributed Reactive Sources (DRS) used in distribution networks for some reasons such as decreasing the energy loss, improving the voltage profile, rectifying the power coefficient and increasing the Capacitance of system. Optimum designing of reactive power or especially the optimum locating of capacitor in distribution networks, performed many times by the power engineers for different aims such as peak power, energy loss, cost decreasing and improving the distribution network reliability (Etemadi and Fotuhi-Firuzabad 2008). Different methods suggested in this domain, from the previous analytical methods (Mekhamer et al. 2002) to innovative and intelligent methods (Dadkhah and Venkatesh 2012).Changing the distribution system structure because of the micro-grids entrance, probable nature of added distributed productions and their ability in reactive power providing, caused to understand the necessity of designing and new strategy in extraction for current distribution systems.In present study, optimum locating and measuring of old reactive sources will reviewed, considering the novel system's circumstances. For this aim, the problems of reactive power designing in distribution systems will formulated, considering the different sides of modern distribution systems. These properties for reactive power designing have not been stated by Etemadi and Fotuhi-Firuzabad 2008; Mekhamer et al. 2002; Dadkhah and Venkatesh 2012in literature.Two objective function considered in this article. First aim is minimizing the annual energy loss in link to the network condition and second aim is maximizing the novel defined index for success performance in islanding situation at feeding-losing condition. The main part of this article is about the researches of optimized reactive power designing in modern distribution systems.

\section{Problem Mathematical Explanation}

In this section, the objective function equations will explained. In this article, the DRS's reactive power presented in general form but they can considered as the capacitor banks that are so affordable. In situations that distributed productions should be used along with power electronic convertors or in situation that capacitors are changeable the same equations, algorithms and analyzes used. Only differences is that the DRS capacities for all load-production states will be variable. Finally, the maximum calculated capacity of DRSs in each situation assumed the optimum capacity of it.

\section{A. Energy Losses}

It is possible to minimize the annual energy losses via the DRSs location optimizing in distribution system. Minimizing the energy losses can be an important goal for network designers. In this article, some cases such as variable characteristic of distributed generations and load profile will be considered for minimizing the annual energy losses. Objective function defined as below: 


$$
\begin{aligned}
F_{1} & =\text { Annual losses of energy } \\
& =\sum_{n=1}^{N} P_{\text {Loss }_{n}} \times \rho_{n} \times h_{n}
\end{aligned}
$$

Where $\mathrm{N}$ is the number of states in a year, $\mathrm{P}_{\text {Loss }} \mathrm{n}$ is the system losses for a distinct time from a year, $\rho_{\mathrm{n}}$ is the related probability state and $h_{n}$ is a time part of related state that is considered one hour here. Via the optimum locating and measuring of DRSs, it is possible to reduce the total energy losses.

\section{B. Micro Grid Success Index}

Micro grids can used in islanding form to provide critical loads at outage of main feeding source and improve the distribution system reliability. One circumstance for success performance in islanding state is as below:

$$
P_{D G} \geq P_{\text {Load }}+P_{\text {Loss }}
$$

Where $\mathrm{P}_{\mathrm{DG}}$ is the generated power by the micro grid DGs, $\mathrm{P}_{\text {load }}$ is the load power in island and $\mathrm{P}_{\text {loss }}$ is the power losses ofthe island and assumed that is 5\% of current load (Jain, Singh, and Srivastava 2013). It assumed that biomass distributed generation units are programmable and is the second circumstance of success operation of micro grid (Pilo, Pisano, and Soma 2011).

$$
P_{B M} \geq 0.6 \times P_{D G}
$$

Where $\mathrm{P}_{\mathrm{BM}}$ is the generated power by the Biomass DGs in micro grid. Equation 2 and 3 are the necessary circumstances for the success performance of micro grid. There are $365 * 3456$ state with different probability for each state. Calculating the defined index for each micro grid, each state calculate separately and zero or one given to each one.

$$
\rho_{\mu G i}=\left\{\begin{array}{ll}
1 & P_{G i} \geq P_{L i} \\
& \& Q_{G i} \geq Q_{L i} \\
& \& \mathrm{~V}_{\min i} \leq V_{i} \leq V_{\max i} \\
& \text { otherwise }
\end{array}\right\}
$$

Where $\mathrm{G}_{\mathrm{i}}$ shows the total generation and $\mathrm{L}_{\mathrm{i}}$ is the total active and reactive power consumption in state $\mathrm{i}, \mathrm{V}_{\mathrm{i}}$ shows the all micro grid buses in state $i$. after the index calculation for each state, using the each state probability, they can sum as below:

$$
\rho_{\mu G}=\sum_{i=1}^{N} \rho_{\mu G i} \times \rho_{i}
$$

Where $\rho_{\mathrm{i}}$ is the state probability. Calculated index in equation 5 is just for a micro grid. For a system with many micro grids the success index obtained by equation 6 .

$$
F_{2}=\frac{\sum_{k=1}^{N o M} \rho_{\mu} G_{k} \times N_{L k}}{\sum_{k=1}^{N o M} N_{L k}}
$$

Where NoM and $\mathrm{N}_{\mathrm{LK}}$ are the number of micro grids and amount of micro grid load respectively.

\section{Compound Objective Function}

Two objective function can be compounded and generate an optimization objective problem:

$$
\min (F), \mathrm{F}=K_{1} \mathrm{~F}_{1}+\mathrm{K}_{2}\left(1-\mathrm{F}_{2}\right)
$$

It should considered that $F_{1}$ and $F_{2}$ should be unit and $F_{2}$ modified to $1-F_{2} . K 1$ and $K 2$ determine that objective function can be annual energy losses, success index of a micro grid or a compound of them. 
Constraints of problem

Constraints of problem contains the below cases:

1) load part equations

$$
\begin{aligned}
& P_{\text {Sub }}+\sum P_{D G_{t}} \pm \sum P_{D E S R_{s}}-\sum P_{\text {Load }_{t}} \\
& =\sum_{i=1}^{\text {nbus }} V_{t, i} \times V_{t, j} \times Y_{i, j} \times \cos \left(\theta_{i j}+\delta_{t, j}-\delta_{t, i}\right) \quad \forall j, t \\
& Q_{S u_{t}}+\sum Q_{D G_{t}} \pm \sum Q_{D E S R_{s}}-\sum Q_{\text {Load }_{t}} \\
& =-\sum_{i=1}^{\text {buus }} V_{t, i} \times V_{t, j} \times Y_{i, j} \times \sin \left(\theta_{i j}+\delta_{t, j}-\delta_{t, i}\right) \quad \forall j, t
\end{aligned}
$$

2) Voltage limitations

$$
\mathrm{V}_{\text {min }} \leq \mathrm{V}_{t, i} \leq \mathrm{V}_{\text {max }} \quad \forall \mathrm{i} \neq 1
$$

3) Feeders capacitance limitations

$$
\mathrm{P}_{\text {sub }} \leq \mathrm{P}_{\text {rated }}
$$

4) discrete values

$$
\mathrm{Q}_{\text {DRS } \_i}=\mathrm{k}_{Q_{i} i} \times Q_{\text {Step }} \quad \forall i
$$

5) Penetration amount of DRS in each Bus

$Q_{\text {DRS } \_i} \leq Q_{\max } \forall i$

6) Total reactive power capacity $\left(Q_{D R S}\right)$

$$
\sum_{i} Q_{D R S s_{-} i}=Q_{D R S}
$$

\section{Problem solution algorithm}

Taboo search TS (Guerrero et al. 2011 and Nunna ; Doolla 2013) is an algorithm based on iteration that uses different memory structures for the optimization problem solving. Optimization solution is vector. Its row consists of considered buses for DRS installation as below:

$$
Q_{D R S}=\left[\begin{array}{llllll}
Q_{D R S_{-} 1} & \ldots & Q_{D R S \_k} & \cdots & Q_{D R S_{\_} N_{C}}
\end{array}\right]
$$

TS starts by an experimental solution and follows towards the neighborhood space. Test solution is a vector similar to $\mathrm{Q}_{\mathrm{DRS}}$, which consists of DRS measurement in each system bus. Changing the parameters of this vector, a set of vectors generated called neighborhood. Solve procedure is as below considering the $K_{1}$ and $K_{2}$ amounts.

1) If $K_{1} \neq 0, \mathrm{~F}_{1}$ should calculated in connected mode to the network.

2) If $K_{2} \neq 0, F_{2}$ calculated for system in islanding state, then the success index calculated via the 4 to 6 equations.

Calculating the $F_{1}$ and $F_{2}$, objective function $F$, calculated for all test solutions in neighborhood and then the search process keep going until the finding best neighborhood.

\section{Implementation and Sensitivity Analysis Studies}

PG\&E 69 bus distribution system used for the algorithm implementation and sensitivity analysis (Tenti et al. 2012). Active and reactive modified power shown in figure 1. In general state the energy losses is equal to 199.56 MWh. The optimum location and named capacity of DGs presented in table 1. 


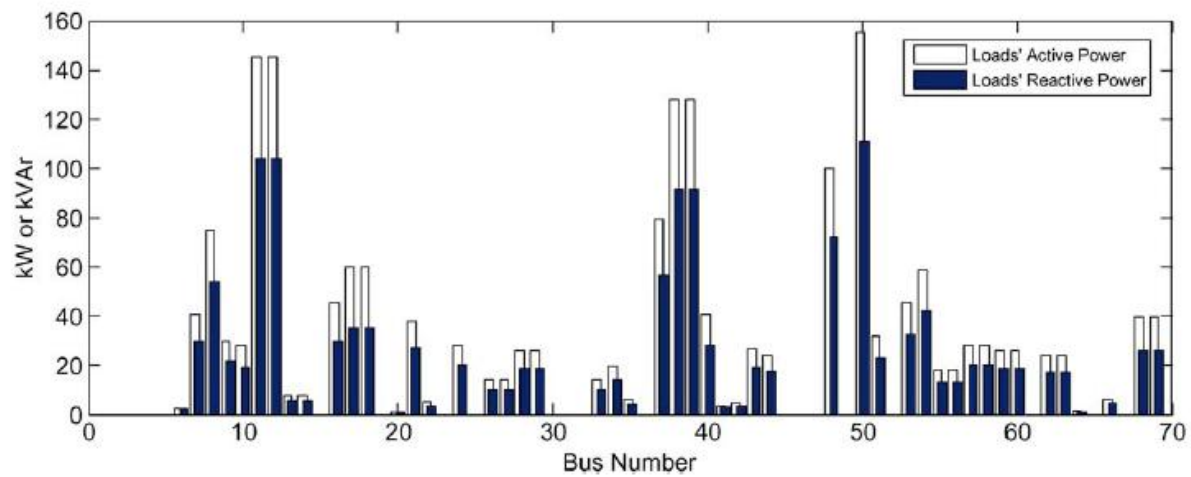

Fig1. The 69 Bus Distribution System Loads

Table1. Optimum selected Buses for the DGs installation

\begin{tabular}{|c|c|c|}
\hline DG Type & Basses & Nominal Capacity(kW) \\
\hline Wind Turbine & $52 ، 43 ، 35 ، 19 ، 16 ، 13$ & $50 ، 50 ، 50 ، 25 ، 25 ، 50$ \\
\hline PVModule & $62 ، 58 ، 56 \cdot 50 ، 36 ، 30$ & 25 ، 25، 25، 25، \\
\hline Production of biomass dispersed & 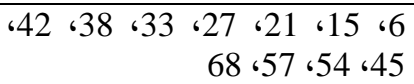 & 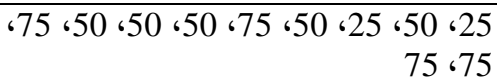 \\
\hline
\end{tabular}

Table2. Micro grids with optimized design

\begin{tabular}{|c|c|c|c|}
\hline Microgrid & Microgrid Basses & (kVA) Peak Times & $\begin{array}{r}\text { Production } \\
(\mathrm{kVA})\end{array}$ \\
\hline & 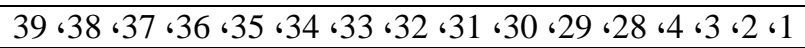 & $427 / 0+j 304 / 6$ & $225 / 0+\mathrm{j} 41 / 1$ \\
\hline & 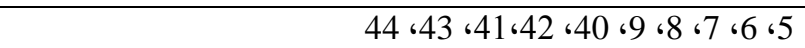 & $246 / 6+j 178 / 9$ & $125 / 0+\mathrm{j} 24 / 7$ \\
\hline & 58 ، 57، 56، 55، 15، 14، 13، 12، & $426 / 0+\mathrm{j} 304$ & $225 / 0+\mathrm{j} 41 / 1$ \\
\hline & 16، 17، 18، 19، 20، 21، 22، 25، 24، 24، 24، 24 ، 24، & $265 / 8+j 171 / 1$ & $125 / 0+\mathrm{j} 24 / 6$ \\
\hline & 54، 53، 52، 51، 50، 46، 46، 49، 47، & $391 / 9+j 280 / 4$ & $200 / 0+\mathrm{j} 41 / 1$ \\
\hline & 59، 60، 61، 62، 63، 64، 65، 68، 67، 69، 69 6 69 & $185 / 6+j 129 / 0$ & $100 / 0+j 24 / 6$ \\
\hline
\end{tabular}

Adding the DGs to the system, the energy losses reduced to $90.58 \mathrm{MWh}$. Then system is divided into six virtual micro grid to minimize the active and reactive power unbalance (Chaouachi et al. 2013). Table 2 shows these six micro grids and their related properties. Figure 2 shows the system mono linear diagram. Considering the annual energy losses and success index as the objective function, the DRSs located in system as optimized form.

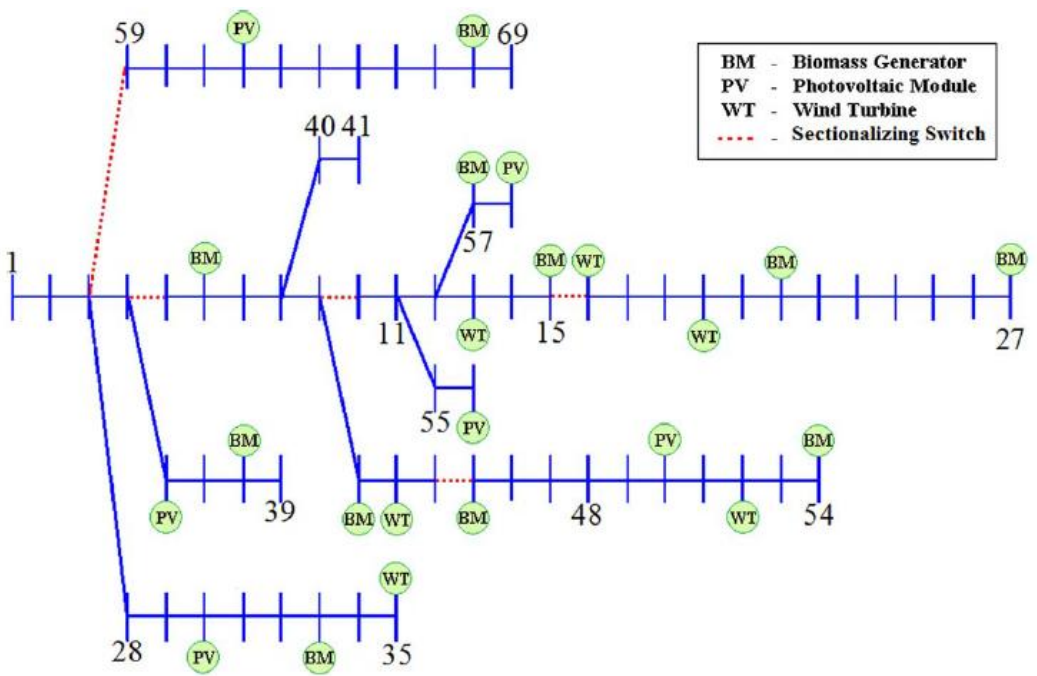

Fig2. The 69 Bus distribution system with location of distributed generations 
Probable Optimization of Reactive Power in distribution systems, in presence of ....

Tabl3. DRS, their locations and capacities in stat A.

\begin{tabular}{|c|c|c|c|}
\hline $\begin{array}{rr}\text { Total } & \begin{array}{l}\text { Capacity } \\
(\mathrm{kVAr})\end{array}\end{array}$ & Basses DRS & Nominal Capacity(kVAr) & $\begin{array}{r}\text { Annual losses of } \\
(\mathrm{MWh}) \text { energy }\end{array}$ \\
\hline 100 & $53 ، 24 ، 3$ & $50 ، 22 ، 25$ & $78 / 93$ \\
\hline 150 & $53 ، 52 ، 51 ، 24 ، 18 ، 3$ & $25 ، 25 ، 25 ، 25 ، 25 ، 25$ & $72 / 43$ \\
\hline 200 & $54 ، 53 ، 50 ، 26 ، 17 ، 4$ & $25 ، 25 ، 50 ، 25 ، 50 ، 25$ & $66 / 88$ \\
\hline 250 & $53 ، 52 ، 50 ، 21 ، 19 ، 17$ ، 53 & $25 ، 25 ، 75 ، 25 ، 25 ، 50 ، 25$ & $62 / 28$ \\
\hline 300 & 57، 53، 51، 50، 21، 19، 51 ، & $25 ، 50 \cdot 25 ، 75 ، 25 ، 25 ، 50 \cdot 25$ & $58 / 59$ \\
\hline 350 & 58،53،52، 50، 24، 18، 12، 13، 50 & 25 ، 25، 25 25، 25، 25، 25، 50، 25 & $55 / 49$ \\
\hline 400 & 57، 53، 52، 51، 50، 27، 22، 15، 52 ، 52 & 25 ، 25، 75، 25، 50، 25، 25، 50، 50، & $52 / 07$ \\
\hline 450 & 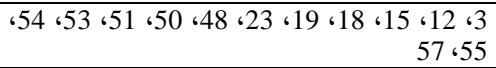 & 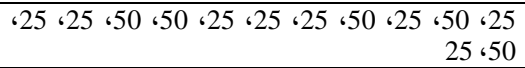 & $51 / 07$ \\
\hline
\end{tabular}

\section{A. Objective function of Annual energy losses (individually)}

In this part, the annual energy losses considered as the objective function only to find the optimum location of DRSs in distributed system. It assumed that total capacitydetermined from $100 \mathrm{KVAr}$ to $450 \mathrm{KVAr}$ with $25 \mathrm{KVAr}$ steps as the optimized form to minimize the annual energy losses. DRSs amount and their location shown in table three. It reveals that annual energy loss decrease from $78.93 \mathrm{MWh}$ to $51.07 \mathrm{MWh}$ in response to DRS increasing.Figure 3 shows the DRS location in situation that total amount of DRS is equal 350 KVAr. In this state, the Buses voltages modified as P.U. [0.9651-1.0016] for all states, adding the DRSs to the system. After one year, it changed to [0.9931-1.0018] P.U.

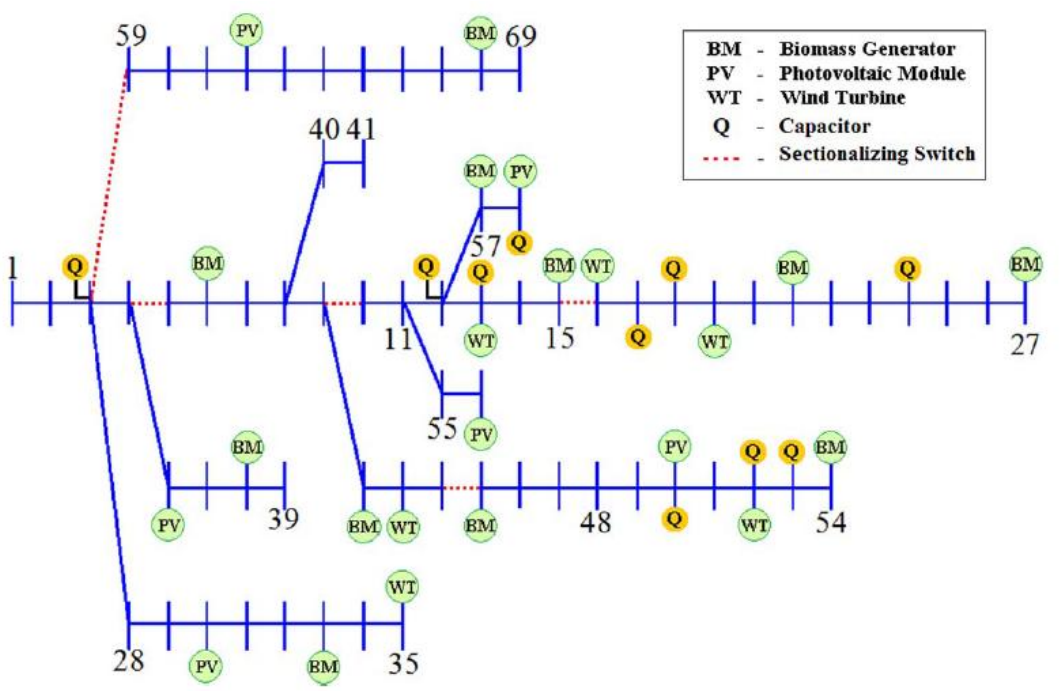

Fig3. DRSs Location in State A.

\section{B. objective function of micro grid success index (individually)}

In this part, only the success index of micro grid considered as the objective function to find the optimum location of DRSs in distribution system. In this part assumed that the total determined capacity, 100$450 \mathrm{KVAr}$, used in distribution system for optimization to success index be maximum. Table 4 shows the Success Index in the entire system in situation that DRSs located in system as optimum form. It can be seen that Success Index increases from $23.88 \%$ to $94.9 \%$. Figure 4 the DRS location has been shown in situation that total amount of them is $350 \mathrm{KVAr}$.

Table4. DRSs, their location and capacities in situation B.

\begin{tabular}{|c|c|c|c|}
\hline $\begin{array}{r}\text { Total Capacity } \\
(\mathrm{kVAr})\end{array}$ & Basses DRS & Nominal Capacity(kVAr) & $\begin{array}{r}\text { Annual losses of } \\
(\mathrm{MWh}) \text { energy }\end{array}$ \\
\hline 100 & $61 ، 37 ، 33 ، 3$ & $25 ، 25 ، 25 ،$ & $23 / 88$ \\
\hline 150 & 63، 33، 29، 25، 25، & $25 ، 25 ، 25 ، 25 ، 25 ،$ & $39 / 47$ \\
\hline 200 & 67، 39، 38، 21، 27، & 50، 25، 25، 25، 25، & $54 / 12$ \\
\hline 250 & 4، 8، 17، 24، 28، 31، 38، 49، 61 38، & 25، 25، 25 ، 25، 25، 25، 25، 25، & $65 / 98$ \\
\hline 300 & 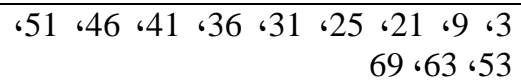 & 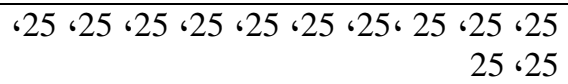 & $71 / 49$ \\
\hline 350 & 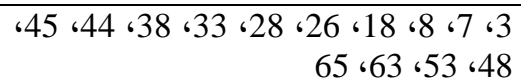 & 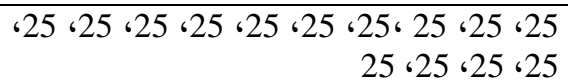 & $80 / 79$ \\
\hline 400 & 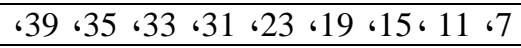 & 25، 50، 25، 25، 25، 25، 25، 25، 25، & $88 / 11$ \\
\hline
\end{tabular}




\begin{tabular}{|c|c|c|c|}
\hline & 43، 47، 61، 62، 67 & 25 25، 50، & \\
\hline 450 & 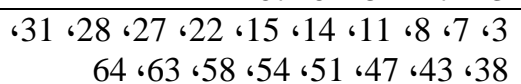 & 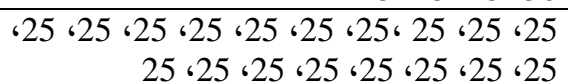 & $94 / 90$ \\
\hline
\end{tabular}

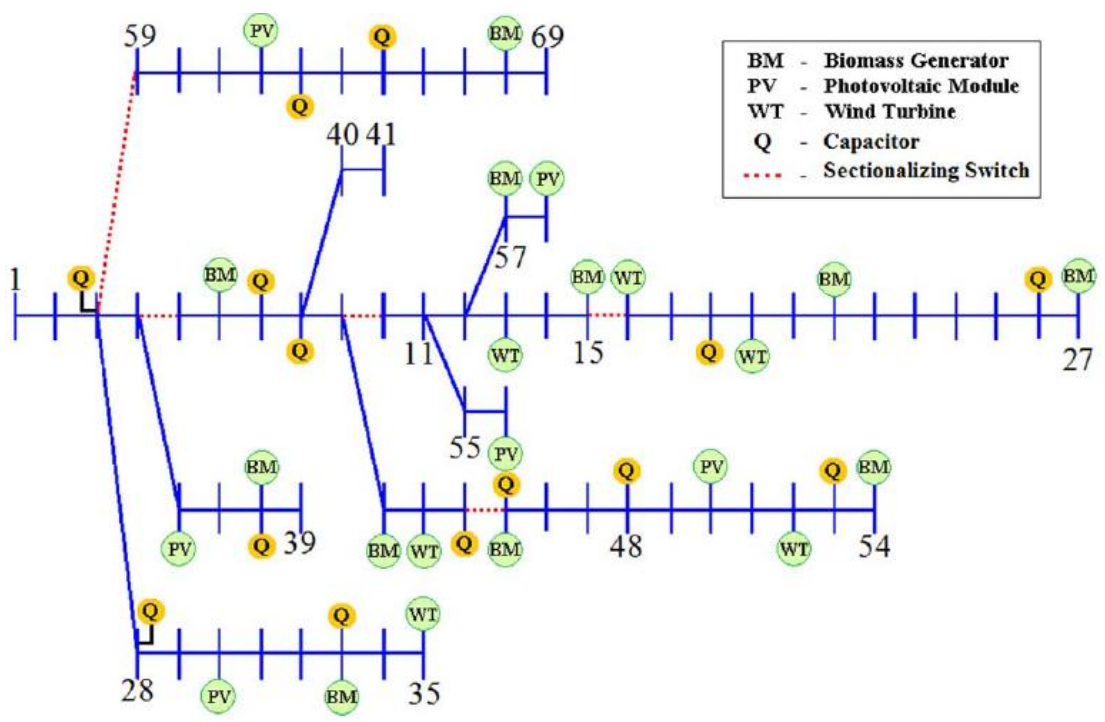

Fig4. Location of DRSs in situation B.

\section{C. considering both objective function}

In this part both objective function are considered together. For this aim, assumed that entire amount of DRSs equal to $350 \mathrm{KVAr}$. This works progressively with $\mathrm{K}_{1}$ increasing and $\mathrm{K}_{2}$ decreasing. The objective function in this situation will be as equation 16:

$F=\left[\begin{array}{l}K_{1} \times\left|\frac{F_{1}-F_{1 O p t}}{F_{1 O p t}}\right| \\ +K_{2} \times\left|\frac{\left(1-F_{2}\right)-\left(1-F_{2 O p t}\right)}{\left(1-F_{2 O p t}\right)}\right|\end{array}\right] \times 100$

Table 5 shows the results of optimum locating probability of DRS in power system. Figure 5 shows the DRS location in situation that total amount of them is $350 \mathrm{KVAr}$.

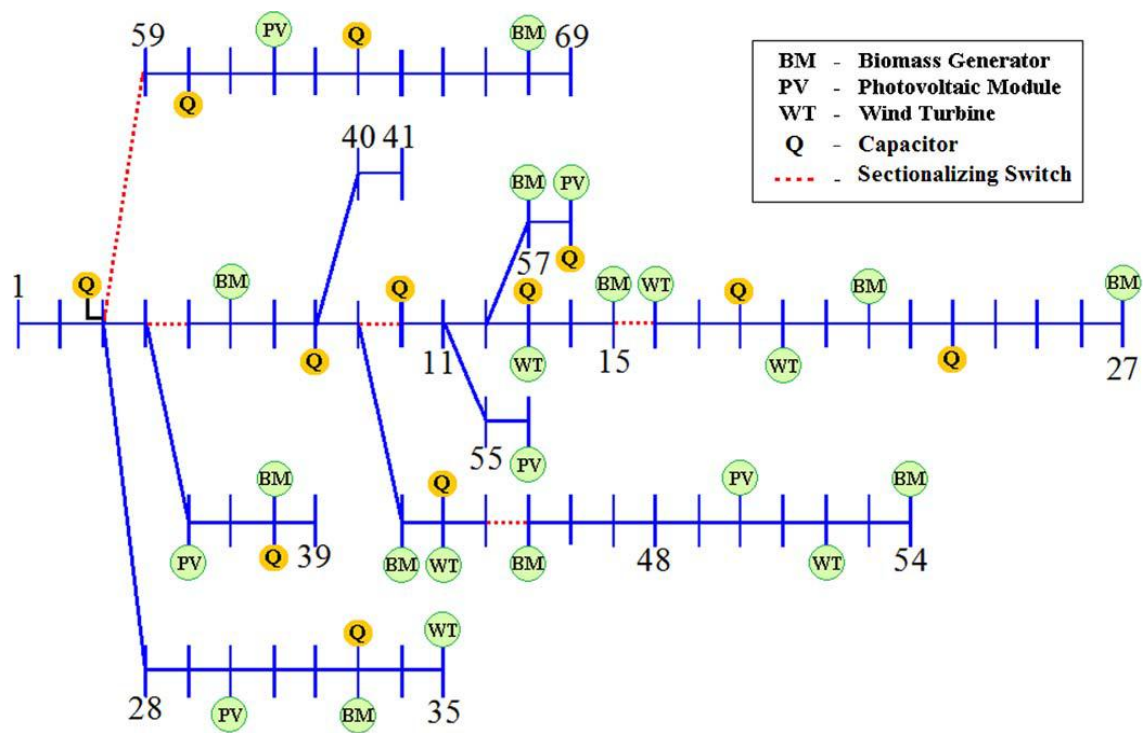

Fig5. DRSs location, considering the both objective function 
Probable Optimization of Reactive Power in distribution systems, in presence of ....

Table5. DRSs, their location and capacities in situation $\mathrm{C}$.

\begin{tabular}{|c|c|c|c|c|}
\hline$K$ & $\bar{K}$ & Basses DRS & Nominal Capacity(kVAr) & $\begin{array}{l}\text { The objective } \\
\text { function }(\%)\end{array}$ \\
\hline 0 & 1 & 65 & r25 25، 25، 25، 25، 25، 25، 25، 25، 25، 25، 25، & $0 / 0$ \\
\hline $0 / 1$ & $0 / 9$ & 68، 60، 60، 60، 53، 50، 40، 40، 30، 30، 63 30، & 25 ، 25، 50، 25، 50، 50، 25، 25، 25 25 & $0 / 0225$ \\
\hline $0 / 3$ & $0 / 7$ & 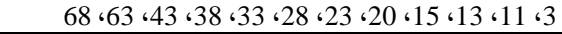 & 25، 25، 25، 25، 25، 25، 25، 25، 25، 25 25، 25 ، 25، & $0 / 1076$ \\
\hline $0 / 4$ & $0 / 6$ & 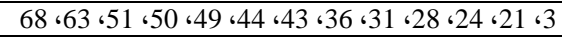 & 25 ، 25، 25، 25، 25، 25 25 25 ، 25 & $0 / 0927$ \\
\hline $0 / 5$ & $0 / 5$ & 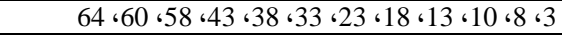 & 25 ، 25، 25، 25، 25، 50، 25، 25، 25، 25 & $0 / 1582$ \\
\hline $0 / 6$ & $0 / 4$ & 3، 11، 14، 15، 18، 20، 28، 37، 39، 42، 43، 68 42، & 25، 25، 25 ، 25، 25، 25، 25، 25، 25، 25، 25، & $0 / 1761$ \\
\hline $0 / 7$ & $0 / 3$ & 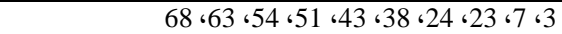 & 25 ، 25، 25، 75، 25، 50، 25، 50، & $0 / 1502$ \\
\hline $0 / 9$ & $0 / 1$ & $\begin{array}{r}60 \\
60\end{array}$ & 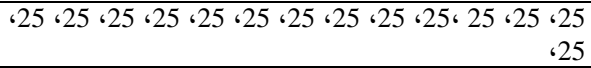 & $0 / 1495$ \\
\hline 1 & 0 & 58، 53، 52، 50، 12، 13، 18، 18، 54 & 25، 25، 25، 25، 25، 25، 25، 50، 25 ، 25، & $0 / 0$ \\
\hline
\end{tabular}

\section{Conclusion}

In this article, a systematic and optimized strategy presented for DRSs optimum locating in micro grids. The TS optimization algorithm, considering the two objective function, has solved the problem. The first one is the annual energy loss and second one is the success index based on active and reactive power quality in addition to voltage limitations. In this article, assessing the some case studies, it has been shown that DRS location and amount have the significant effect on micro grid successful operation. Therefore, this problem should be reviewed for temporary part time distributed generation units.

\section{References:}

[1]. Chaouachi, Aymen, Rashad M Kamel, Ridha Andoulsi, and Ken Nagasaka. 2013. 'Multiobjective intelligent energy management for a microgrid', IEEE Transactions on Industrial Electronics, 60: 1688-99.

[2]. Dadkhah, Maryam, and Bala Venkatesh. 2012. 'Cumulant based stochastic reactive power planning method for distribution systems with wind generators', IEEE Transactions on Power Systems, 27: 2351-59.

[3]. Etemadi, AH, and M Fotuhi-Firuzabad. 2008. 'Distribution system reliability enhancement using optimal capacitor placement', IET generation, transmission \& distribution, 2: 621-31.

[4]. Guerrero, Josep M, Juan C Vasquez, José Matas, Luis García De Vicuña, and Miguel Castilla. 2011. 'Hierarchical control of droopcontrolled AC and DC microgrids-A general approach toward standardization', IEEE Transactions on Industrial Electronics, 58: $158-72$.

[5]. Jain, Naveen, SN Singh, and SC Srivastava. 2013. 'A generalized approach for DG planning and viability analysis under market scenario', IEEE Transactions on Industrial Electronics, 60: 5075-85.

[6]. Mekhamer, SF, ME El-Hawary, SA Soliman, MA Moustafa, and MM Mansour. 2002. 'New heuristic strategies for reactive power compensation of radial distribution feeders', IEEE Transactions on Power Delivery, 17: 1128-35.

[7]. Nunna, HSVS Kumar, and Suryanarayana Doolla. 2013. 'Multiagent-based distributed-energy-resource management for intelligent microgrids', IEEE Transactions on Industrial Electronics, 60: 1678-87.

[8]. Pilo, Fabrizio, Giuditta Pisano, and Gian Giuseppe Soma. 2011. 'Optimal coordination of energy resources with a two-stage online active management', IEEE Transactions on Industrial Electronics, 58: 4526-37.

[9]. Tenti, Paolo, Alessandro Costabeber, Paolo Mattavelli, and Daniela Trombetti. 2012. 'Distribution loss minimization by token ring control of power electronic interfaces in residential microgrids', IEEE Transactions on Industrial Electronics, 59: 3817-26. 